Michele Rocha Kadri ${ }^{1}$ Julio Cesar Schweickardt ${ }^{1}$

\section{As Organizações da Sociedade Civil no enfrentamento à AIDS no Amazonas, Brasil}

\author{
Community-based organizations and the aids epidemic \\ in Amazonas state, Brazil
}

Abstract The scope of this paper was to analyze the perception of community-based organizations and their contributions to the history of tackling Aids in Amazonas State. It involved qualitative research with the use of oral and documental sources. Data were collected between June and September 2013 by means of semi-structured interviews with the leaders of eight organizations that work or worked with more vulnerable communities. Based on Discourse Analysis the conclusion drawn is that that the organizations perceive two distinct phases since the decentralization of funds from the Sexually-Transmitted Diseases Aids and Viral Hepatitis Department to the local leaders. The first phase was marked by the strengthening of organizations, collective empowerment and active political participation. The current phase has seen the distancing between organizations, a loss of political momentum and weakening of common response and organization. Key words Public health policies, Aids, Social movement, Non-governmental organizations
Resumo Este estudo objetivou analisar a percepção que as Organizações da Sociedade Civil fazem de sua contribuição na história do enfrentamento à AIDS, no Amazonas. Trata-se de pesquisa qualitativa com uso de fontes documentais e orais. Os dados foram coletados entre junho e setembro de 2013. Utilizou-se técnica de entrevistas com roteiro semiestruturado com as lideranças de oito organizações que trabalham/trabalharam com grupos mais vulneráveis. A partir da análise do discurso, concluiu-se que com a descentralização de recursos do Departamento de DST, AIDS e Hepatites Virais para as Coordenações locais, as Organizações reconhecem dois momentos distintos: um primeiro momento de fortalecimento organizacional, engajamento coletivo e participação política ativa; e um momento atual de distanciamento entre as Organizações e desarticulação política e, consequentemente, enfraquecimento do movimento social na luta contra AIDS no Amazonas.

Palavras-chave Políticas públicas de saúde, Aids, Participação comunitária, Organizações não-governamentais
${ }^{1}$ Centro de Pesquisa Leônidas e Maria Deane, Fiocruz. R. Teresina 476, Adrianópolis. 69057 070 Manaus AM Brasil. michele.kadri@gmail.com 


\section{Introdução}

O processo de redemocratização do país e as discussões do movimento da reforma sanitária no início da década de 1980 trouxeram referenciais que nortearam a política governamental do combate à AIDS no país. A solidariedade impulsionou a organização da sociedade civil para fazer frente ao desconhecimento sobre a doença e à ineficiência da política de assistência do Estado aos primeiros casos ${ }^{1}$. Solidariedade compreendida "como uma ação coletiva cuja finalidade é preservar a cidadania dos doentes e dos grupos mais atingidos". O enfrentamento à AIDS era (e é!) uma intervenção de promoção dos direitos humanos.

Evidenciando dilemas morais da sociedade associados à dimensão da incidência e letalidade da doença, toda gama de preconceito as pessoas vivendo com HIV prenunciava, como diz Seffner, a morte por AIDS antes dela mesma ${ }^{2}$, pondo à prova a capacidade da sociedade de demonstrar solidariedade. É uma doença carregada de significado social e cultural, afetando não somente a vida pessoal daqueles infectados pelo vírus, mas também trazendo profundas repercussões na vida e nas relações em sociedade. No campo da saúde, Cáritas Relva Basso ${ }^{3}$ aponta que, "ao contrário da forma tradicional de criação e implementação dos programas de saúde pública, o Programa de AIDS nasceu da iniciativa das pessoas afetadas pelo agravo e não de parâmetros que enquadram um agravo como um problema de saúde pública".

Dessa forma, quando apenas 4 casos haviam sido notificados, a Secretaria de Saúde de São Paulo já organizava o primeiro Programa de AIDS do país, em $1983^{4}$. Tentava-se dar resposta a uma demanda que vinha da sociedade ${ }^{5,6}$, especialmente do grupo mais afetado pela doença e também organizado politicamente, os homossexuais. No Brasil, os movimentos sociais encontravam terreno propício ao diálogo com a saúde no ideário de reforma sanitária.

Jonathan Mann ${ }^{7}$, coordenador da primeira iniciativa global para AIDS (Global Program on AIDS, da OMS, em 1986) e comprometido com ativismo dos direitos humanos, ao fazer uma discussão entre Saúde Pública e Direitos Humanos, conclui que não se pode analisar a epidemia exclusivamente sobre um dos lados em particular, sob o risco de não se conseguir criar uma política efetiva de controle. Olhando a doença unicamente sob o prisma de saúde pública, ações como restrição de circulação de pessoas, isolamento, testagem compulsória se justificariam, embora tais medidas sejam claramente uma ameaça aos direitos individuais. Por outro lado, o extremismo pela proteção desses direitos poderia levantar bons argumentos para justificar a negligência de governos em não adotar qualquer medida de controle da epidemia.

Hoje, o Programa Conjunto das Nações Unidas para AIDS (UNAIDS) reconhece que a mobilização e a participação social são elementos centrais e catalizadores que devem sustentar ações de qualquer programa de longo prazo, tanto na redução da incidência quanto na melhoria do cuidado para pessoas já infectadas ${ }^{8}$. Nessa orientação, o diálogo e a cooperação entre sociedade civil e ações de governo são essenciais e altamente recomendados para o sucesso de um Programa de AIDS. Apesar de tão estratégica, ainda hoje, no Amazonas, são escassas as fontes que apresentam e debatem a participação dos movimentos sociais na construção do enfrentamento à AIDS. É necessário conhecer tais movimentos para então considerá-los como agentes mobilizadores sociais no enfrentamento da epidemia, respeitando suas missões institucionais que os legitimam frente àqueles que devem representar.

O Departamento de DST, AIDS e Hepatites Virais ${ }^{9}$ do Ministério da Saúde define que Organizações de Sociedade Civil (OSC) são organizações que "representam a sociedade nos processos de análise e discussão das políticas públicas do setor no país” e que sua participação na elaboração de políticas públicas "contribui para o exercício da cidadania e para o controle social". Portanto, o termo OSC não se restringe a instituição formalmente constituída (pessoa jurídica), mas também a grupos, redes, fóruns que atuam no combate à epidemia.

Considerando a relevância do protagonismo das pessoas infectadas e/ou afetadas pelo HIV, este estudo se propôs analisar a contribuição das Organizações da Sociedade Civil no enfrentamento à epidemia, debatendo ainda sua participação no controle social no programa de AIDS, no estado. O presente artigo é parte de um trabalho de natureza histórica sobre a AIDS no Amazonas, assim, a análise feita considera que as mudanças ocorridas no movimento de AIDS, no estado, foram moldando-se em função do quadro epidemiológico, mas principalmente do redirecionamento da política de controle e assistência no Brasil. 


\section{Metodologia}

Cada OSC tem ação focada em grupo(s) específico(s). Dessa forma, na tentativa de captar diferentes percepções e atuações, foram selecionados informantes de cada grupo vulnerável, cuja contribuição para o Programa tenha sido registrada em documentos do Ministério da Saúde e/ou da Coordenação Estadual DST/AIDS, ao longo do tempo em análise, totalizando oito entrevistas. Para assegurar a representatividade dos significados, todos os sujeitos da pesquisa contam pelo menos cinco anos de ativismo na área, sendo em média quatorze anos de trabalho. Portanto, os sujeitos foram pessoas que conhecem e compreendem profundamente a realidade estudada ${ }^{10}$.

No país desde 1994, as diversas OSC se reúnem em Fóruns estaduais como forma de fortalecer a rede de participação e cooperação interinstitucional ${ }^{4}$. Dessa forma, considerou-se o Fórum Amazonense de OSC/AIDS como um espaço comum de interação entre as OSC, sendo que algumas de suas lideranças também foram entrevistadas.

A técnica de entrevistas individuais deu flexibilidade necessária para agendar os encontros de acordo com a disponibilidade de cada um dos informantes no espaço onde eles se sentiam confortáveis, permitindo explorar em profundidade detalhes que emergiram em uma conversa mais reservada. As entrevistas foram conduzidas a partir de um roteiro semiestruturado que permitiu adicionar perguntas baseadas nas informações trazidas pelo entrevistado, esclarecendo pontos e explorando detalhes de modo a confirmar o entendimento do significado das respostas ${ }^{11}$. As entrevistas levaram em média pouco mais de $1 \mathrm{~h}$.

Um número limitado de pontos de vista a respeito da contribuição do movimento social no enfrentamento à epidemia no estado foi identificado, confirmando que as "representações não surgem de mentes individuais, mas que em alguma medida elas são resultado dos processos sociais" ${ }^{12}$. O acúmulo de informações no conjunto das entrevistas permitiu um saturamento das informações e uma compreensão sobre o posicionamento estratégico e político de cada OSC, e inferir como isto norteia seu ativismo.

$\mathrm{Na}$ análise dos dados privilegiou-se a busca de sentidos e significados partindo da fala dos participantes e respeitando a integralidade do que expressam espontaneamente ${ }^{13}$. Através da análise do discurso, entendendo o contexto no qual os fatos relatados ocorreram, foi traçada uma correlação entre as mudanças ocorridas no direcio- namento da política nacional e a consequência no posicionamento estratégico das OSC. A análise se deteve exclusivamente na reflexão que as lideranças das OSC fazem de suas contribuições institucionais e coletivas ao longo da história da epidemia no Estado, sem utilização de qualquer outro método de mensuração e avaliação de processo ou impacto de resultados.

Fontes documentais como ata de fundação, planos e relatórios de ação, e-mails e correspondências das OSC foram coletados e serviram principalmente para organizar cronologicamente e complementar as informações trazidas nas entrevistas.

Respeitando todos os aspectos éticos, o projeto foi submetido e aprovado pelo Comitê de Ética em Pesquisa da Universidade Federal do Amazonas. Todos os sujeitos assinaram o Termo de Consentimento Livre e Esclarecido.

\section{A participação do movimento social e a luta antiaids no Amazonas: controle da sociedade ou pela sociedade?}

A Sociologia utiliza o conceito de Controle Social no sentido coercitivo para descrever uma forma de poder do empresariado ou do Estado sobre as massas. Em significado precisamente oposto, a Constituição Brasileira de 1988 utiliza o mesmo termo com sentido de assegurar a participação da população na elaboração, implementação e fiscalização das políticas sociais ${ }^{14}$.

Essa reinterpretação do conceito pela Constituição ampliou a possibilidade do exercício da cidadania, em completo acordo com contexto de democracia que se reinstalava no país àquela altura. Com o apaziguamento de grande parte de seus anseios a partir da Constituição de 1988, inaugura-se uma nova etapa da relação da sociedade com o Estado. Nesse momento os movimentos sociais abandonam a posição de enfrentamento e assumem uma postura de articulação e parceria com o Estado ${ }^{15}$. No âmbito federal, já em 1985, o Ministério da Saúde estabelece as diretrizes para o Programa de Controle da Síndrome de Imunodeficiência Adquirida, sob a coordenação da Divisão Nacional de Dermatologia Sanitária e, em 1988, o Programa Nacional de AIDS é desvinculado daquela Divisão ${ }^{4}$.

Na década de 1980, as intervenções das OSC eram mais voltadas a pressionar o Governo na luta pelos direitos das Pessoas Vivendo com HIV/ AIDS (PVHA), desenvolvendo ações mais políticas do que técnicas ${ }^{16}$. A partir da assinatura dos 
acordos com Banco Mundial em 1993, com sua estrutura de monitoria de ações e recursos, os projetos das OSC tomam um foco mais voltado à intervenção comportamental, menos político e mais técnico. Todavia, mensurar resultados de ação política e intervenção cultural nem sempre é possível. A “despolitização” das OSC é uma das consequências dessa mudança estratégica no foco de atuação ${ }^{17}$. Ao desenvolver atividades com financiamento governamental, as OSC acabam fazendo parte de uma política de governo, uma vez que sua atuação fica condicionada a prioridades definidas quer seja pelo Governo Federal, Estadual ou Municipal ${ }^{16}$. Os projetos aprovados são aqueles que atendem as diretrizes da ideologia vigente. A crítica feita é que esse modelo tendo seu financiamento vinculado ao governo ameaça o controle social almejado no SUS. Nesse entendimento, o sentido de controle social aproximase do conceito definido pela Sociologia: controle da sociedade pelo Estado.

Por outro lado, essa parceria Estado-OSC pode ser uma alternativa de descentralização da política. Através da atuação das OSC, a presença do Estado é sentida mais rapidamente na população contribuindo com caráter bem peculiar ao público para o qual ela é voltada. Dificilmente, ações do Estado podem chegar tão próximas dos grupos aos quais se destinam, sem ajuda de elementos que facilitam o diálogo. Daí porque a participação social tanto no planejamento quanto na execução de ações é tão fortemente recomendada por consensos internacionais, dentre eles a UNAIDS.

Ao fazer levantamento da história do movimento antiaids, verificou-se que também no Amazonas os mesmos fenômenos aconteceram, inclusive o processo de despolitização e de descentralização.

As primeiras Organizações que se mobilizaram no Amazonas, a partir 1989, nasceram com propósitos e atuação bem definidos. A Associação Amavida, a primeira delas, dedicou-se ao trabalho com profissionais do sexo e também mobilização na mídia para esclarecimento da população sobre AIDS ${ }^{18}$. Já o Grupo Gay do Amazonas, fundado em $1992^{19}$ e atualmente chamado Associação Amazonense GLBT, alinhou seu ativismo na promoção dos direitos humanos ao discurso de prevenção e esclarecimento do público LGBT sobre a epidemia. A Associação dos Soropositivos do Amazonas voltava-se para ações de assistência social aos soropositivos. A Rede de Amizade e Solidariedade ${ }^{20}$ promovia ações de educação através do teatro para público em geral, mas também de- senvolvia um trabalho de orientação aos usuários da Fundação de Medicina Tropical (FMT), instituição de referência no Amazonas para cuidado e tratamento DST/HIV.

$\mathrm{O}$ ativismo das OSC nesse primeiro momento concentrava-se em duas frentes: por um lado, promoção, embora precariamente, de ações de informação e prevenção junto ao seu público-alvo; por outro lado, reivindicação, pelo acesso a assistência apropriada das autoridades de saúde:

Logo no inicio era muito difícil, era mais difícil do que tá sendo hoje [...] Antigamente, a gente brigava, a gente ia pra imprensa, a gente denunciava, a gente brigava porque a gente não tinha apoio. A gente discutia com o secretário de saúde, discutia com o diretor da Fundação (FMT) [...] (Ativista A)

À luta. As pessoas batiam panela mesmo, iam pra rua, gritavam [...] luta pelos direitos humanos, porque as pessoas eram muito maltratadas [...] os ricos iam pra fora se tratar, os pobres mesmo, morriam e não sabiam nem o que é que tinham. (Ativista F)

As OSC adotavam postura mais politizada e de confronto com as autoridades de saúde, reivindicando principalmente qualidade na assistência aos soropositivos. O tema chamava muito atenção da imprensa e as OSC utilizavam frequentemente esses meios para dar voz a suas denúncias. Avaliam que, embora não houvesse ação coordenada entre elas, cada uma tinha uma ação ativa e notável na luta pelos direitos das PVHA.

A partir de 1993, algumas receberam fundos vindos dos acordos do Ministério da Saúde com o Banco Mundial. No entanto, elas tinham fontes alternativas para financiar suas atividades, desde parcerias com instituições internacionais, como era caso do Amavida, até promoção de eventos beneficentes e venda de produtos, como exemplo a ASA-AM. Embora os recursos (humanos e financeiros) fossem mais limitados, os ativistas que se comprometiam com a causa engajavam-se efetivamente nas ações promovidas.

Com a implantação, a descentralização dos recursos e da gestão, a partir da Política de Incentivo em 2002, através do Plano de Ações e Metas (PAM), quando as OSC passaram a ter assegurado financiamento de projetos diretamente pelas coordenações estaduais e municipais, parece ter sido impulsionada a criação/formalização de OSC no estado. A possibilidade de acesso a recurso público assegurado no PAM foi entendido como ‘benefício' pelas OSC:

A gente foi ver o que a gente precisava. Precisava de que? Assistência? Então, onde é que a gente vai buscar assistência? A gente precisa de recurso? Como 
a gente pode chegar pra buscar esse recurso? Aí que veio a ideia da gente fazer o estatuto, registrar o estatuto e correr atrás dos benefícios. (Ativista B)

A AIDS tem muito dinheiro, é a prima rica de todas as doenças (Ativista $\mathrm{C}$ )

Esse é o dinheiro da AIDS, o nosso dinheiro! (Ativista E)

Todas as OSC entrevistadas reconheceram que os financiamentos de projetos pelo governo facilitaram sua capacidade de organização institucional. Com o trabalho das OSC fortalecido cria-se um espaço de transformação das estruturas sociais por meio da transformação da consciência política ${ }^{21}$. Lideranças mais antigas das Organizações entrevistadas reconheceram que o ingresso de novos atores a partir de 2002 elevou o nível de discussão política sobre direito das PVHA no Amazonas. Nas palavras de um dos entrevistados: os ativistas agora sabem de tudo, sabem todas as leis que estão aí. (Ativista B).

Estabelece-se o conflito entre autonomia e colaboração. No campo prático, esse paradigma vem se colocando como antagônico e se mostra muito presente na fala de todas as OSC pesquisadas. O novo desafio que se apresentou ao movimento social a partir de então foi encontrar um caminho no qual sua autonomia organizacional fosse preservada, apesar da aliança com o Estado definir as regras do jogo. Era importante colaborar com o Estado para assegurar que suas intervenções atendessem às demandas sociais, mas igualmente fundamental preservar suas missões institucionais e capacidade de exercer controle social conforme entendido na Constituição: controle do Estado pela sociedade. Preservar autonomia organizacional é condição essencial para garantia do direito de controle social pelas OSC.

Os ativistas parecem ter consciência que como movimento social as OSC devem exercer controle da política de AIDS no Amazonas, no entanto nenhuma soube apontar com clareza como este pode ser operacionalizado. Há entendimento generalizado que o principal instrumento de participação social são as reuniões de planejamento do PAM. Quando questionados, por exemplo, sobre participação nos Conselhos de Saúde, limitaram a dizer que o Fórum tem representação, sem saber informar qual tem sido a participação ou qualquer outro ponto que tenha sido levado para discussão nessa instância:

O controle social já foi tão bem no Brasil que é o melhor programa. Já o daqui [do Amazonas] tenho minhas dúvidas. (Ativista C)

Entre os anos de 2002 e 2003, seis grupos se organizaram em rede ou ONG, todos na capital, incluindo o Fórum Amazonense de OSC/AIDS. Com o crescimento dos movimentos locais e as novas diretrizes federais, o ativismo AIDS no Estado foi ganhando visibilidade e reconhecimento das autoridades de saúde. Parafraseando um dos ativistas sai de uma coisa feita à mão para algo mais profissional. Em 2003, o Fórum assume suplência da Associação dos Doentes Renais Crônicos, no segmento usuário, no Conselho Estadual de Saúde ${ }^{22}$.

Daquela época pra cá, a mudança que houve no movimento social... é, naquela época realmente existia luta. Porque o HIV não era tão conhecido como é hoje, a questão do preconceito era muito forte, ainda é até hoje, mas é menos. Nós não tínhamos a medicação que temos hoje [...]. (Ativista F)

A gente já brigou muito, hoje em dia a gente senta e conversa. Mas é por aí que eu acho que tem que ser, sentar e resolver. Não adianta a gente ir logo para o embate. (Ativista A)

'Sentar e conversar' expressa bem a transição de uma postura de enfrentamento para postura de articulação e parceria com o Estado. O fortalecimento técnico e financeiro das OSC também contribuiu para a consolidação de sua legitimidade junto às instâncias governamentais ${ }^{6,15}$.

Os relatos confirmam que o Fórum Amazonense OSC/AIDS sempre foi um espaço importante de discussão política, embora alguns considerem também que na tentativa de articular ações entre afiliados, ele burocratizou e engessou atuação das OSC a ele afiliadas. Ressalta-se aqui uma característica bem peculiar do ativismo brasileiro contra AIDS: a representatividade dessas Organizações não é quantitativa, mas sim de valorização das minorias, o que em parte também explicaria a multiplicidade de grupos atuantes na mesma área ${ }^{6}$. No entanto, a partir da organização das OSC no Fórum, o Amazonas começou a se fazer presente em encontros e espaços nacionais, como na Comissão de Articulação Movimentos Sociais (CAMS) e na Comissão Nacional de AIDS (CNAIDS). Em 2007, o II Encontro Nacional de PVHA aconteceu em Manaus, demonstrando a organização institucional e articulação política que o movimento da AIDS alcançou no Amazonas. Essas foram conquistas muito valorizadas pelos ativistas, acreditando que elas contribuíram para aumentar a credibilidade do movimento e fortalecer sua ação política frente às autoridades de saúde local.

Analisando as propostas finais do V Encontro Regional ONG/AIDS (ERONG), também acontecido em Manaus em 2009, chama atenção que, das onze propostas aprovadas no documento 
final, apenas duas tinham caráter exclusivamente de melhoria de assistência a PVHA. Todas as outras foram decisões sobre representatividade política do movimento AIDS, do nível regional ao nacional.

As pessoas 'tavam' muito querendo brigar por causa de dinheiro, que é o principal motivo. Eu nunca vi alguém brigar porque alguém não foi fazer algo... é sempre mais meu cargo do que assistência. (Ativista C)

Eu não vejo as ONGs lutar pelos seus usuários, principalmente nessa PAM, meu Deus do céu, a briga é por passagem. 'Ah! Eu quero ir pra tal lugar, vai ter passagem num sei pra onde'. Eu acho que não é bem por aí. (Ativista D)

A gente percebe claramente que existia mais amor próprio, amor pelo seu companheiro. Hoje a gente não vê mais isso, infelizmente [...] os ativistas hoje se acomodaram, a verdade é essa! (Ativista E)

Se por um lado o PAM permitiu melhor organização institucional das OSC, é presente nos relatos e fontes documentais os frequentes desentendimentos e a disputa de fundos do Plano. Essa disputa por representatividade política acabou por enfraquecer o movimento de AIDS, distanciando progressivamente as OSC umas das outras e deixando esquecidas as bandeiras da solidariedade e do controle social. A disputa por passagens aéreas foi questão que frequentemente esteve presente em todos os relatos e correspondências resgatadas, representando um ponto de forte tensão dentro do movimento.

A respeito da ameaça ao controle social, as Organizações identificam que esses recursos funcionam como cala a boca para a sociedade civil, embora reconheçam também que o recurso permitiu sua estruturação organizacional e que ainda hoje suas atividades acontecem basicamente com recursos vindos do Plano, como uma "PAMdependência":

A gente sabe que eles não dão um dinheiro pra gente, eles dão um 'cala a boca'. Eles dão pra gente ficar caladinho, e a gente não queria isso. A gente queria sim fazer o trabalho, mas ter uma voz. (Ativista $\mathrm{B}$ )

Ao focarem suas ações na prestação de serviço e elaboração de projetos que respondam a demanda de financiamento ditado pela Coordenação Estadual, as OSC olvidam suas missões institucionais e isso aumenta não só conflitos internos, mas também conflitos entre as Organizações que acabam por concorrer entre si na busca pelos mesmos recursos ${ }^{15}$.

$\mathrm{Na}$ investigação sobre a percepção que as OSC fazem em geral do movimento social an- tiaids, o roteiro de entrevista leva a uma análise em perspectiva histórica. Nessa perspectiva, o movimento de AIDS no passado é analisado de forma coletiva, como um único movimento. Já no presente, as Organizações avaliam sua atuação individualmente, a identidade é dada pelo o que é percebido como diferente do outro e não mais pela representação em comum do movimento. Talvez essa diferenciação tão espontaneamente expressa demonstre momentos distintos: a partir de 2003, nos primeiros anos do PAM, a ação era coletiva e as OSC reconhecem o movimento social como um só e com importantes conquistas na promoção direitos das PVHA, e; nos últimos três anos, com agravamento de disputas internas, as Organizações vêm se isolando e trabalhando em ações individuais, distanciando-se de discussões políticas.

Atualmente, diferenciam-se três posicionamentos distintos, definidos principalmente a partir da questão de financiamento do governo:

No primeiro bloco, encontram-se aquelas que, embora recebam recursos públicos, não dependem do financiamento do PAM para execução de suas atividades. Estas acabam por desenvolver ações isoladas, abrindo mão das discussões sobre o Programa para beneficio do bem coletivo. Neste grupo estão aquelas que são financeira e ideologicamente autônomas. Expressam-se na ideia cada ONG deve lutar pelo bem estar de seus usuários, fechando-se no atendimento às demandas do seu público-alvo.

Em outro posicionamento, há OSC que trazem em seu discurso entendimento claro do seu papel como controle social, tanto na fiscalização quanto no planejamento das ações. Ainda assim, adotam uma postura de pouco diálogo com as autoridades de saúde, tentando manter ações paralelas e independentes do poder público, por entender que suas ações não devem substituir atuação do governo. Embora financeiramente dependentes, preservam sua autonomia ideológica. Expressam-se no pensamento a gente não tá pra fazer o trabalho do governo.

Por fim, há OSC que atuam muito próximo as autoridades de saúde, preenchendo abertamente uma lacuna não assumida pelo estado e/ou legitimando suas ações. Entendem que visibilidade social significa ter reconhecimento das autoridades de saúde. No entanto, ao se identificarem na fala, a Coordenação aprova muito o nosso trabalho, reconhecem também que mudanças na gestão das instituições públicas sempre acarretam algum prejuízo também na sua própria organização institucional. Nesse último grupo estão aquelas 
financeira e ideologicamente dependentes, comprometendo perigosamente sua autonomia.

Se assumida radicalmente qualquer uma dessas posturas, o diálogo com a sociedade e poder público fica comprometido, inviabilizando o controle social e enfraquecendo o princípio da solidariedade que tão profundamente marcou a história do movimento social de AIDS no Brasil.

Ao submeter sua autonomia às condições impostas por editais, as OSC subjugam sua missão institucional, perdendo razão de sua existência e colocando em dúvida sua condição de representatividade de um grupo social. Tais distorções fazem que, por exemplo, uma organização cuja missão priorize assistência à toxicodependentes, concentre esforços na conscientização da população em geral sobre importância da testagem para hepatite viral.

As OSC que fazem uma leitura mais ampla e crítica desse contexto acabam por desacreditar do movimento, assumindo postura de distanciamento tanto do poder público quanto das outras Organizações. Tudo isso parece estar conduzindo progressivamente as lideranças para um abandono real e/ou ideológico do movimento social.

O sentimento comum presente em todos os relatos é que o movimento social de luta contra a AIDS hoje no Amazonas parece viver uma crise de representatividade. As OSC se isolaram e limitaram sua atuação a pequenos projetos, quase sempre financiados pelo poder público. O discurso de todas foi permeado por uma descrença generalizada na situação atual e um saudosismo pelas conquistas realizadas em tempos idos, embora, curiosamente, uma chama de esperança ainda permaneça presente no discurso dos ativistas mais antigos. $\mathrm{O}$ vigor de uma nova geração parece fazer falta ao movimento e essa ausência de novas lideranças também foi apontada pelas OSC como fator de preocupação.

Devido às conquistas que a gente já teve em relação ao HIV, muitos estão achando assim: Ah! Já lutei muito, agora deixa pros novos que tão chegando [...]. A verdade é essa: o movimento AIDS no Amazonas está morrendo. E não sou só eu, muitos de nós também tá achando isso. A verdade é essa, a gente não sabe nem o que fazer. (Ativista E)

O Fórum OSC/AIDS seria a instância legítima onde tais posicionamentos poderiam ser discutidos e articulados política e ideologicamente. No entanto, em alguma medida, alguns entrevistados relatam não se reconhecerem representados neste espaço, embora continuem a participar das reuniões e algumas ações.
A partir dos dados levantados, verificouse que o ativismo no campo da AIDS tem dois níveis de atuação. O primeiro é o "trabalho de formiguinha", com ações que aproximem a população ao serviço de saúde, de forma que a eficiência do trabalho das OSC pode ser comprovada, conferindo assim legitimidade à sua atuação conforme missão institucional. São essas ações que justificam sua existência, norteiam seu posicionamento estratégico e devem sustentar seu discurso político. O segundo nível é a articulação política feita em rede e é, principalmente, esse trabalho que torna o movimento de AIDS visível à sociedade em geral, criando possibilidades de entendimento interinstitucional e diálogo com instituições e lideranças públicas.

Para uma contribuição efetiva e consistente no enfrentamento à epidemia no Amazonas e no controle social do programa, as OSC devem pensar seu posicionamento político e estratégico nesses dois níveis: fortalecimento de suas missões institucionais e da articulação em rede, sendo que ambas deveriam ser pautados no princípio da solidariedade.

\section{Considerações finais}

O empréstimo da fala de um ativista para dar título a esse artigo ao expressar-se na ideia "lutar para sobreviver" evidencia o esforço permanente para existência das organizações com fins não lucrativos, quer seja no âmbito real, quer seja no aspecto simbólico (cumprir sua missão institucional). No caso das organizações antiaids essa luta se confunde com a própria luta pela existência subjetiva de alguns sujeitos dessa pesquisa que vivem com o vírus.

Numa primeira análise, os relatos pareciam bastante egocêntricos e personalizados, levando ao questionamento sobre o lugar do qual o sujeito falava. O maior desafio ao construir essa análise foi identificar nas entrevistas o que era posicionamento institucional e o que era relato pessoal de experiência. No momento, da coleta de dados, um reposicionamento foi necessário para dar vazão ao que de fato era pertinente aos anseios dos informantes. À parte das tentativas em trazer o relato para uma ordem sequencial e analítica, todos os sujeitos se implicavam fortemente na história institucional das Organizações que representam. Ao abrir espaço e dar vazão para que os sujeitos falassem e refletissem sobre o ativismo, os entrevistados acabam por dar senti- 
do, em alguma medida, à sua própria existência. Em suas palavras: se eu deixar o movimento social, eu vou morrer. (Ativista B)

Para apreender a percepção que as OSC fazem de si mesmas, foi necessário considerar a impossibilidade de separar relatos pessoais de institucionais, real do simbólico, para compreender que as informações trazidas se articulam em dimensões complementares e não antagônicas.

A ação coletiva conecta pessoas com problemas similares, favorece engajamento no combate à AIDS e fortalece a luta por acesso e tratamento de qualidade a todos que deles necessitem. A sensibilização para testagem, conhecimento acerca do tratamento, redução de estigma, promoção de equidade, monitoramento da qualidade do acesso e tratamento são elementos que devem estar presentes em programas efetivos de combate a $\mathrm{AIDS}^{8}$. Programa eficaz é aquele no qual a sociedade civil organizada é verdadeiramente parceira e não apenas objeto de intervenção.

Assim como em todo o país, também no Amazonas ficou claro que as mudanças da Política Nacional, especialmente quanto ao financiamento às OSC, contribuíram não somente para criação de novas Organizações, mas principalmente norteou suas ações de modo que respon- dessem aos editais de seleção de projeto, ou seja, à demanda do programa estadual. Os relatos $\mathrm{CO}^{-}$ letados denunciam de forma velada ou explicita discordâncias significativas no posicionamento político e estratégico das OSC, situação que parece ter se agravado nos últimos três anos. Uma conclusão possível é que como consequência da concorrência pela participação nos financiamentos governamentais, o movimento social antiaids do estado vem se enfraquecendo e se desarticulando política e estrategicamente.

A respeito do controle social, embora as OSC tenham um discurso afiado sobre o tema, não lhes parece sensível os mecanismos políticos para seu exercício. O Programa de AIDS no Amazonas parece girar em torno da Coordenação Estadual, sendo que grande parte das ações inclusive do movimento social são ditadas pelas orientações de editais de financiamento. Como exercício complementar dessa problemática, ainda há espaço para desdobramento da pesquisa, no sentido de mensurar com instrumentos próprios para monitoria de ações e avaliação de efetividade do trabalho que vem sendo realizado tanto pelo governo quanto pelas Organizações da Sociedade Civil no enfrentamento da AIDS no Amazonas.

\section{Colaboradores}

MR Kadri trabalhou na pesquisa, concepção e redação do texto; JC Schweickardt na metodologia e revisão final. 


\section{Referências}

1. Grangeiro A, Silva LL, Teixeira PR. Resposta à AIDS no Brasil: contribuições dos movimentos sociais e da reforma sanitária. Rev Panam Salud Publica 2009; 6(1):87-94.

2. Seffner F. O jeito de levar a vida. Trajetórias de soropositivos enfrentando a morte anunciada[dissertação]. Porto Alegre: UFRGS; 1995.

3. Basso CR. Programa de DST/AIDS no SUS. In: Negri B, Viana ALD, organizadores. O Sistema Único de Saúde em 10 anos de desafio. São Paulo: Sobravime; 2002. p. 43-58.

4. Galvão J. 1980-2001: uma cronologia da epidemia de HIV/AIDS no Brasil e no mundo. Rio de Janeiro: ABIA; 2002. Coleção ABIA - Políticas públicas; v.2.

5. Pereira AJ, Nichiata LYI. A sociedade civil contra a Aids: demandas coletivas e políticas públicas. Cien Saude Colet 2011; 16(7):3249-3257.

6. Ramos S. O papel das ONGs na construção de políticas de saúde: a Aids, a saúde da mulher e a saúde mental. Cien Saude Colet 2004; 9(4):1067-1078.

7. Mann J. Saúde Pública e Direitos Humanos. Physis 1996; 6(1-2):135-145.

8. Schwartländer B, Stover J, Hallett T, Atun R, Avila C, Gouws E, Bartos M, Ghys PD, Opuni M, Barr D, Alsallaq R, Bollinger L, Freitas M, Garnett GR, Holmes C, Legins K, Pillay Y, Stanciole AE, McClure C, Hirnschall G, Laga M, Padianet N. Towards an improved investment approach for an effective response to HIV/AIDS. Lancet 2011; 377(9782):2031-2041.

9. Brasil. Ministério da Saúde (MS). O que são organizações da sociedade civil. [acessado 2012 jul 1]. Disponível em: http://www.aids.gov.br/pagina/o-que-sao-organizacoes-da-sociedade-civil

10. Fraser MTD, Gondim SMG. Da fala do outro ao texto negociado: discussões sobre a entrevista na pesquisa qualitativa. Paidéia 2004; 14(28):139-152.

11. Britten N. Entrevistas Qualitativas. In: Pope C, Mays N, organizadores. Pesquisa Qualitativa na Atenção à Saúde. Porto Alegre: Artmed; 2009. p. 23-31.

12. Bauer MW, Gaskell G. Pesquisa qualitativa com texto, imagem e som. 7a ed. Rio de Janeiro: Vozes; 2008.
13. Minayo MCS. O desafio do conhecimento: pesquisa qualitativa em saúde. 11ª ed. São Paulo: Hucitec; 2008.

14. Bravo MI, Rocha F, Maksud I, Kamel L, organizadoras. Políticas públicas de DST/AIDS e controle social no Estado do Rio de Janeiro: capacitando lideranças e promovendo a sustentabilidade das respostas frente à AIDS. Rio de Janeiro: ABIA; 2006.

15. Gonçalves CF. As casas de apoio no contexto das politicas públicas para DST/AIDS no Estado de São Paulo, período de 1996 a 2003 [dissertação]. São Paulo: Universidade de São Paulo; 2006.

16. Galvão J. Aids no Brasil: agenda de construção de uma epidemia. Rio de Janeiro: Editora 34; 2000.

17. Terabe SH. Avaliação do grau de sustentabilidade das ONGs que executaram projetos financiados pelo Programa Nacional de DST e AIDS: perspectivas dos stakeholders [dissertação]. Rio de Janeiro: Escola Nacional de Saúde Pública; 2009.

18. Brasil. Ministério da Saúde (MS). Catálogo de Organizações Não Governamentais. Brasília: MS; 1997.

19. Associação Amazonense de Gays, Lésbicas e Travestis. Dossiê Violação de Direitos e Violência Contra Homossexuais no Amazonas. Manaus: Associação Amazonense de Gays, Lésbicas e Travestis; 2004.

20. Rede de Amizade e Solidariedade às Pessoas Vivendo com HIV/AIDS. Ata de Fundação em 11 abril 1997. Manaus: Rede de Amizade e Solidariedade às Pessoas Vivendo com HIV/AIDS; 1997.

21. Altman D. Power and community: Organizational and cultural responses to AIDS. London: Taylor\&Francis; 1994.

22. Amazonas. Conselho Estadual de Saúde (CES). Ata da $107^{a}$ Reunião do Conselho Estadual de Saúde de $25 \mathrm{fev}$ 2003. Manaus: CES; 2003.

Artigo apresentado em 10/03/2014

Aprovado em 08/10/2014

Versão final apresentada em 10/10/2014 
